\title{
Apoptosis-Inducing Effect of a New Bisphosphonate, YM529, on Various Hematopoietic Tumor Cell Lines
}

\author{
Shozo Nishida, * Shigeru Kikuichi, Hisae Haga, Shohei Yoshioka, Masonobu Tsubaki, Katsuki FujII, \\ and Kiyohiro IRIMAJIRI
}

Kinki University School of Pharmaceutical Sciences; 3-4-1 Kowakae,Higashiosaka, Osaka 577-8502, Japan. Received June 6, 2002; accepted September 24, 2002

\begin{abstract}
In recent years, it has been reported that bisphosphonates inhibited the cell cycle of myeloma cells to inhibit cell proliferation directly, and it was also reported that bisphosphonates induced apoptosis of myeloma cells in vitro. Recently, YM529 was developed as a new third-generation bisphosphonate. In our experiment, we investigated whether YM529 showed an antitumor effect on hematopoietic tumor cell lines other than myeloma, and we compared YM529 with YM175, which had a relatively more potent antitumor effect than that of existing bisphosphonates. We found that YM529 inhibited cell proliferation in various hematopoietic tumor cell lines (acute promyelocytic leukemia cell line HL-60, chronic myeloid leukemia cell line K562, histiocytic lymphoma cell line U937, lymphoblastic leukemia $T$ cell line Jurkat, acute lymphoblastic leukemia $T$ cell line MOLT-4, lymphoblastic leukemia B cell line CCRF-SB) including myeloma (myeloma cell line HS-Sultan) dose-dependently and timedependently to a degree equivalent or superior to that in myeloma, and induced apoptosis at a lower concentration as compared with YM175. We confirmed many dead cells as well as apoptosis based on the detection of the nuclei with separate globular structure, the activation of caspase-3, and the decrease in mitochondrial transmembrane potential. Therefore, it is concluded that further utilization of YM529 can be expected against hematopoietic tumor cells in the future.
\end{abstract}

Key words YM529; bisphosphonate; apoptosis; hematopoietic tumor cell

At present, bisphosphonates are being used widely for the treatment of bone metabolic diseases ${ }^{1)}$ such as osteoporosis, ${ }^{2}$ Paget's disease, ${ }^{3)}$ and hypercalcemia associated with a malignant tumor. Bisphosphonates act via direct inhibition of the bone resorption activity of osteoclasts. ${ }^{4-6)}$ In addition, bisphosphonates were reported to have inhibited indirect bone resorption mediated by their influence on other cells, such as juvenile osteoclasts and osteoblasts, ${ }^{7-9)}$ and their inhibition of adhesion of fibroblasts, macrophages, and breast cancer cells also has been reported. ${ }^{10-13)}$ In recent years, it has been reported that bisphosphonates induce apoptosis of myeloma cells in vitro. ${ }^{14-16)}$ The newly developed YM529 retains an imidazopyridine group, which is a heterocyclic aromatic, and has 10-100 times stronger inhibitory effects on bone resorption compared with existing bisphosphonates. ${ }^{17,18)}$ Moreover, a potent antitumor effect of YM529 on myeloma cells has been reported. ${ }^{19)}$ Considering the accumulation of bisphosphonates in bones, a stronger apoptosis-inducing effect of this agent on bone metastatic tumors or hematopoietic tumors can be expected, suggesting the possibility of the clinical use of this agent as an antitumor drug. In our experiment, we evaluated the cell viability and apoptosis-inducing effect of YM529 on various hematopoietic tumor cell lines, and compared the efficacy of each with that of YM175, which has been reported to have relatively potent antitumor effects relative to existing bisphosphonates.

\section{MATERIALS AND METHODS}

Chemicals YM529 (1-Hydroxy-2-(imidazo-[1,2-a]pyridin-3-yl) ethylidene bisphosphonic acid monohydrate and YM175 ((cycloheptylamino)-methylene bisphoshonic acid) were supplied from Yamanouchi Pharmaceutical Co., Ltd. (Tokyo, Japan). These bisphosphonates were dissolved in phosphate buffered saline (PBS, $0.05 \mathrm{M}, \mathrm{pH} 7.4$ ), filtrated through Syringe Filters (0.45 micron, IWAKI GLASS) and used for various assays described below.

Cell Culture HL-60, Jurkat, K562, MOLT-4, and U937 cells were obtained from Riken Cell Bank. CCRF-SB and HS-Sultan were obtained from Dainippon-Pharmacy. These cells were cultured in RPMI1640 medium (Nissui) supplemented with $10 \%$ fetal calf serum (Gibco), penicillin $(100 \mu \mathrm{g} / \mathrm{ml}$, Meiji), streptomycin (100 units/ml, Meiji), and $25 \mathrm{~mm}$ Hepes ( $\mathrm{pH} 7.4$, Wako) in an atmosphere containing $5 \% \mathrm{CO}_{2}$.

Cell Viability Cell viability was assessed by the tetrazolium dye method using TetraColor ONE assay kit (Seikagaku). Cells $\left(2 \times 10^{4}\right.$ cells/well $)$ were plated in 96 well plates and incubated with various doses of YM529 or YM175 described above for 24, 48 and $72 \mathrm{~h}$. Absorbance was measured at $492 \mathrm{~nm}$ using a microplate reader (SK601, Seikagaku). Apoptosis was assessed by the demonstration of the activation of caspase- 3 .

Analysis of Nuclear Morphology All cell lines were cultured for $24 \mathrm{~h}$ before treatment with $200 \mu \mathrm{M}$ YM175 and YM529 and grown in the presence of the bisphosphonates for $2 \mathrm{~d}$. On the third day, the cells were fixed with $10 \%$ formaldehyde in PBS for $5 \mathrm{~min}$ before staining them with Hoechst $33258(1 \mu \mathrm{g} / \mathrm{ml})$ at $37^{\circ} \mathrm{C}$ in the dark. For fluorescence microscopy, cells were cytospun onto slides and examined using a universal microscope (Olympus) with UV illumination. Apoptotic cells were defined on the basis of characteristic changes in the nuclear morphology.

Cytofluorometric Determination of Mitochondrial Transmembrane Potential $\Delta \Psi_{\mathrm{m}}$ To evaluate mitochondrial transmembrane potential $\Delta \Psi_{\mathrm{m}}$, cells $\left(5 \times 10^{5} / \mathrm{ml}\right)$ were incubated with 3,3-dihexyloxacarbocyanine iodide (40 nM $\mathrm{DiOC}_{6}$ in PBS, Molecular Probes) for $5 \mathrm{~min}$ at $37^{\circ} \mathrm{C}$ followed by analysis on a flowcytometer (FACScan, Becton Dickinson). DiOC6 fluorescence was recorded in FL1. 
Mesurment of Caspase-3 Proteolytic Activity Caspase-3 like enzyme activity was measured by proteolytic cleavage of the fluorogenic substrate DEVD-AFC using the ApoTarget Caspase-3 Protease Assay Kit (BioSource International Inc.). HL-60 cells were treated with or without YM175 or YM529 for 24 or $48 \mathrm{~h}$. And then, cells were collected, washed in PBS and lysed in lysis buffer in the above kit. For the assay, a solution of cell lysates containing $50 \mu \mathrm{M}$ substrate was incubated at $37^{\circ} \mathrm{C}$ for $1 \mathrm{~h}$. The release of AMC from the substrate was measured fluorimetrically using a fluorescence spectrophotometer (F-4010, Hitachi) with an excitation wavelength of $505 \mathrm{~nm}$ and an emission wavelength of $400 \mathrm{~nm}$. The results were corrected for protein content of the lysates and expressed as change in proteolytic cleavage of the substrate (pM) for $1 \mathrm{~h}$ per mg protein.

The protein content of the cell lysate was determined using the BCA protein assay kit (Pierce).

Statistical Anlysis Statistical anlysis was performed with the Mann-Whitney-test and a value of $p<0.01$ was considered statistically significant.

\section{RESULTS}

Cell Viability YM175 or YM529 was administered to various hematopoietic tumor cell lines, and the cell viability of both drugs was compared by the tetrazolium salt method. Both drugs showed cell viability in all the cell lines dose-dependently and time-dependently (Fig. 1). Table 1 lists the $\mathrm{IC}_{50}$ of YM175 and YM529 against all the cell lines. Against cell lines other than CCRF-SB, YM529 was confirmed to have a more potent inhibitory effect of cell viability than YM175. Against HL-60, HS-Sultan, K562, and U937, in which a remarkable effect of YM175 treatment was observed, YM529 was confirmed to have a more potent inhibitory effect of cell viability (Fig. 1, Table 1). In addition, against Jurkat and MOLT-4, in which the inhibitory effect of cell viability of YM175 treatment was mild, YM529 was observed to decrease the cell survival rate markedly, and was confirmed to have a potent inhibitory effect of cell viability on these cell lines (Fig. 1, Table 1).

Changes in Nuclear Morphology YM175 and YM529 treatment for $2 \mathrm{~d}$ caused changes in nuclear morphology consistent with induction of apoptosis in various hematopoietic

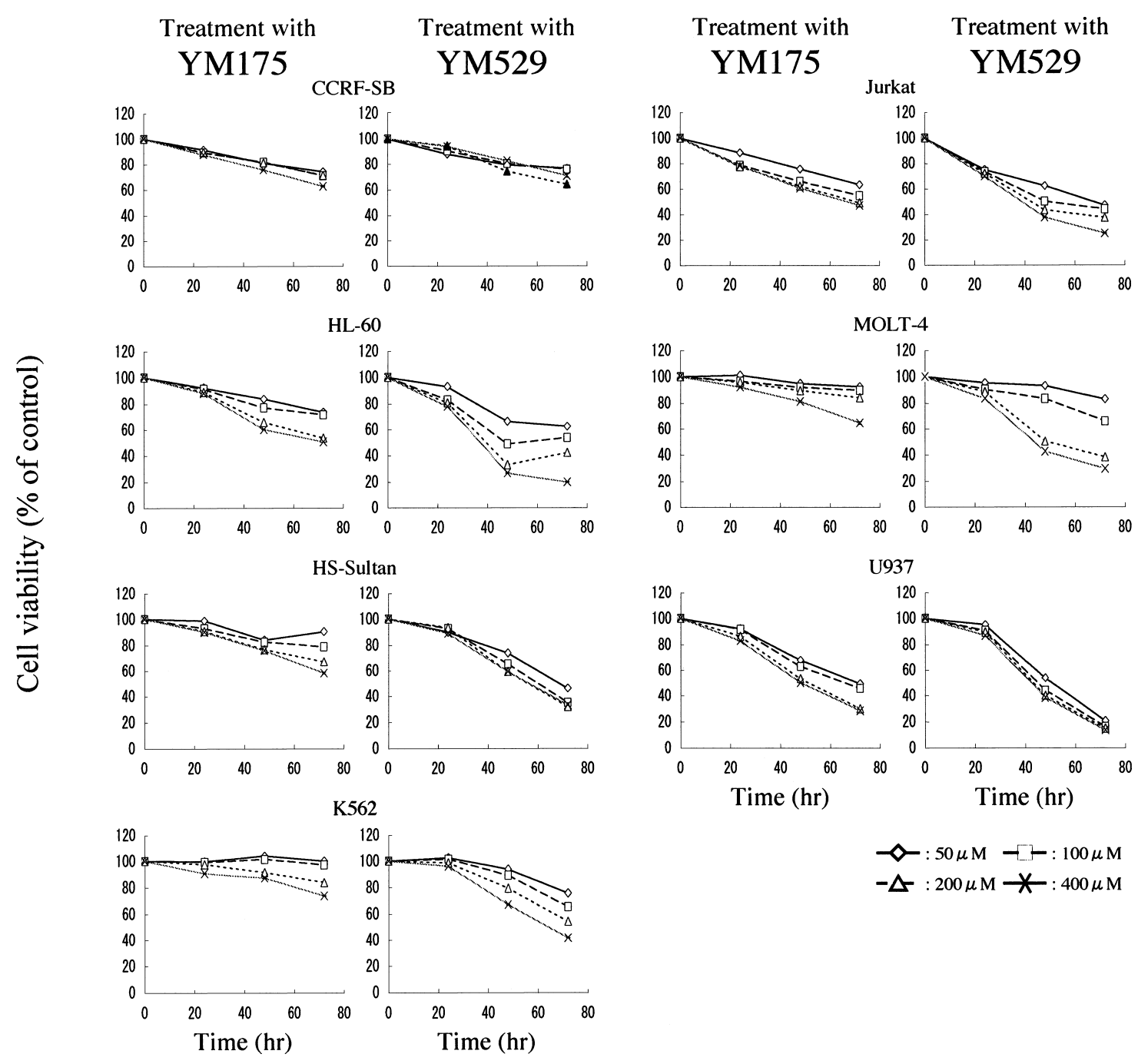

Fig. 1. Cell Viability of YM175 and YM529 on Various Cell Lines Measured by Tetrazolium Assay

The cells were treated with 50,100, 200, and $400 \mu \mathrm{m}$ bisphosphonates for 24 to $72 \mathrm{~h}$. Bisphosphonates induced inhibition of proliferation in all cell lines dose-dependently and time-dependently. The results are expressed as percent of control. 
tumor cell lines. When stained with Hoechst 33258, many cells had nuclei with separate globular structures (Fig. 2). These features are highly characteristic of apoptotic cells. Similar changes in nuclei were observed in all the cell lines treated with YM175 (Fig. 2).

Caspase-3 Activity After YM529 or YM175 treatment, the activation of caspase- 3 in all the cell lines used in the experiment was observed over time (Fig. 3). In all the cell lines, the activation was slow at $24 \mathrm{~h}$ after YM529 or YM175 treatment, but at $48 \mathrm{~h}$, the activation of caspase- 3 developed rapidly in YM529 treatment as compared with YM175 treatment.

Mitochondrial Transmembrane Potential After treatment with $200 \mu \mathrm{M}$ YM175 or YM529, a decrease in mitochondrial transmembrane potential was observed in all the

Table 1. $\mathrm{IC}_{50}$ of YM175 and YM529

\begin{tabular}{lcc}
\hline \hline \multirow{2}{*}{ Cells } & \multicolumn{2}{c}{$72 \mathrm{~h}$ after treatment } \\
\cline { 2 - 3 } & YM175 $(\mu \mathrm{M})$ & YM529 $(\mu \mathrm{M})$ \\
\hline CCRF-SB & $>400$ & $>400$ \\
HL60 & 383 & 106 \\
HS-Sultan & 139 & 2.28 \\
Jurkat & $>400$ & 250 \\
K562 & 222 & 47.6 \\
MOLT-4 & $>400$ & 168 \\
U937 & 50.5 & 0.07 \\
\hline
\end{tabular}

cell lines used in this experiment (Fig. 4). A decrease in membrane potential was observed in MOLT- 4 beginning $12 \mathrm{~h}$ after the addition of YM529, and in other cell lines, the decrease in membrane potential was observed at $24-48 \mathrm{~h}$ after the addition of YM529 (Fig. 4). These results suggest that the route of the implementation of apoptosis in cell lines used in the experiment induced by YM529 and YM175 was mediated by mitochondria, and YM529 was confirmed to induce a decrease in mitochondrial transmembrane potential earlier than YM175.

\section{DISCUSSION}

In recent years, it has been reported that bisphosphonates inhibited the cell cycle of myeloma cells to inhibit cell proliferation directly, and it was also reported that bisphosphonates induced apoptosis of myeloma cells, ${ }^{14-16)}$ macrophage cells, ${ }^{20)}$ and breast cancer cells ${ }^{21)}$ in vitro. Bisphosphonates exhibit inhibitory effects on bone resorption as well as having antitumor effects, thereby suggesting the possibility of their providing a beneficial effect on tumor disease associated with bone destruction. Recently, YM529 was developed as a new third-generation bisphosphonate. According to reports, ${ }^{17,18)}$ YM529 has an approximately 100 -fold more potent inhibitory effect on bone resorption as compared with the second-generation bisphosphonate pamidronate, and an approximately 10 -fold more potent inhibitory effect as compared with the third-generation bisphosphonate YM175. We

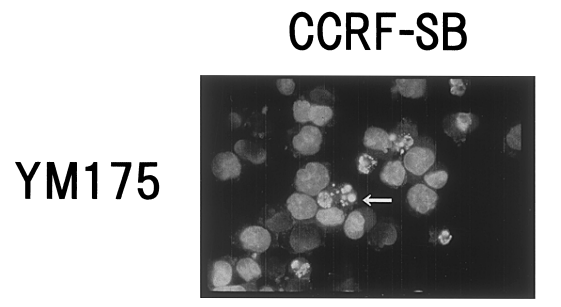

YM529
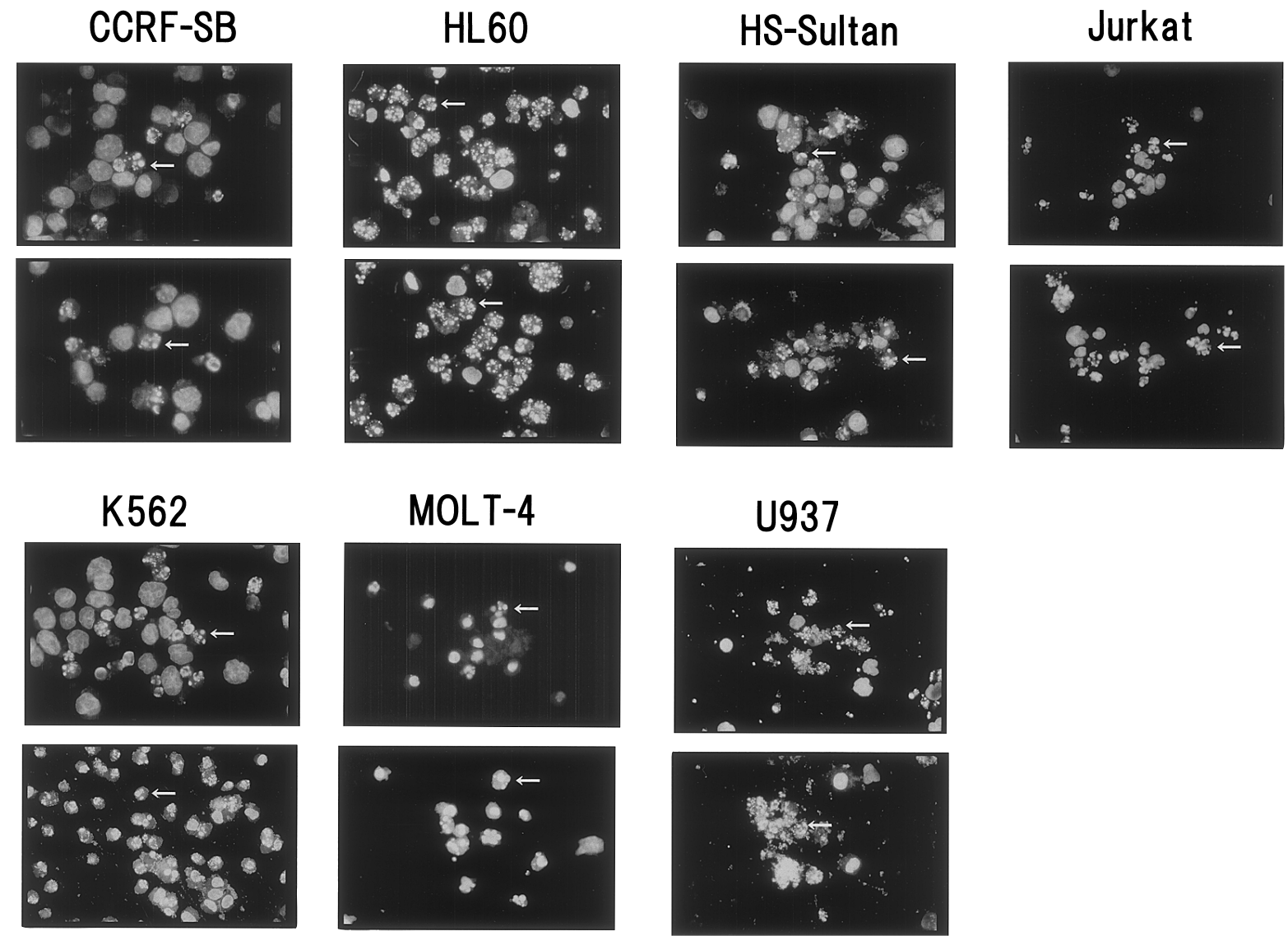

Fig. 2. Changes in Nuclear Morphology

Fluorescence micrographs $(40 \times 3.3)$ of the nuclei of various hematopoetic cell lines following treated with $200 \mu \mathrm{M}$ of YM175 and YM529 respectively for $2 \mathrm{~d}$. Apoptotic nuclei are marked with arrows. 

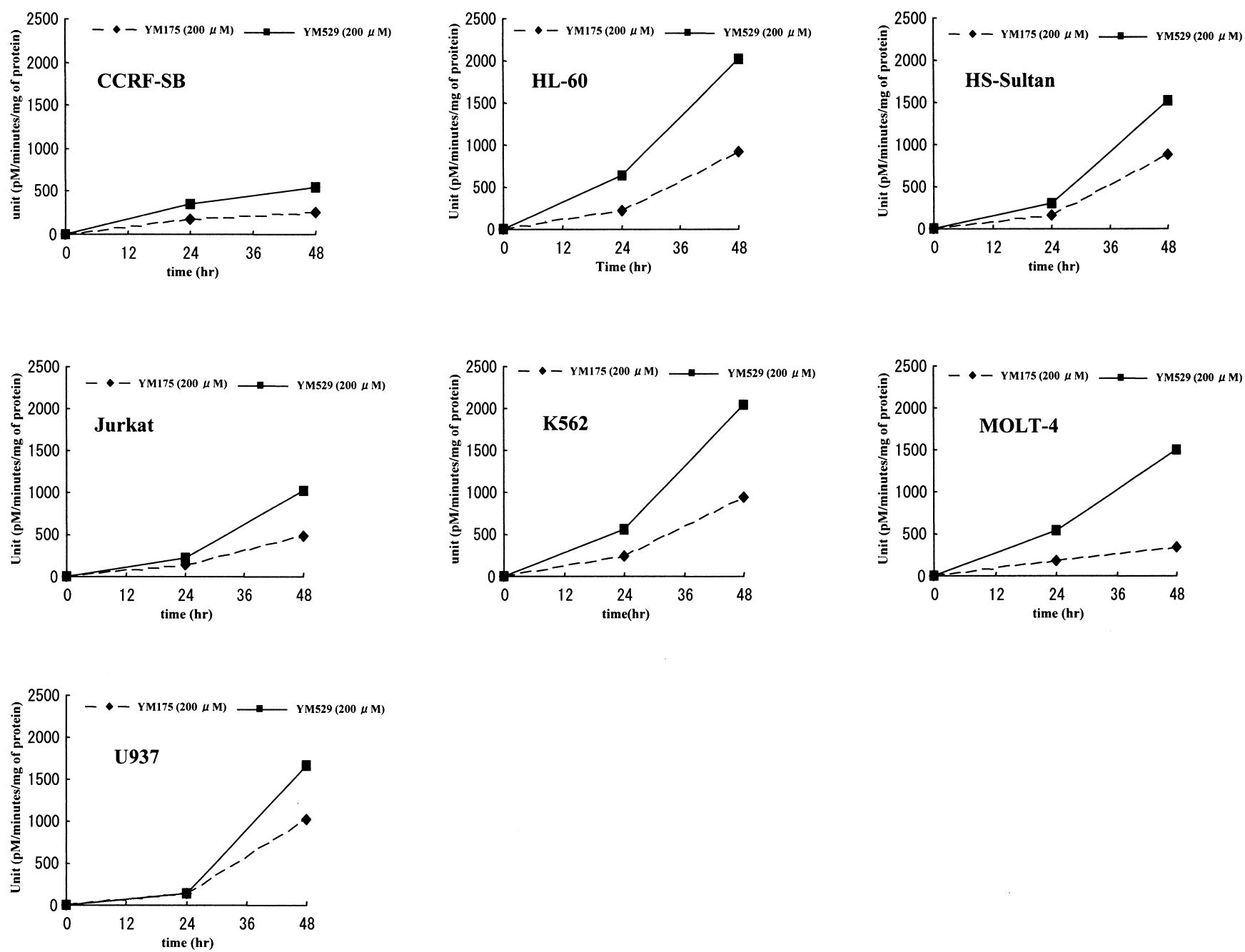

Fig. 3. Induction of Caspase 3-Like Activity Associated with YM175 and YM529-Induced Apoptosis

Caspase-3 activity was expressed as the picomols (proteolytic cleavage of the caspase-3 substrate DEVD-AFC) per hour per mg of protein.

confirmed that YM175 and YM529 inhibited cell proliferation in hematopoietic tumor cell lines, including myeloma cell lines, dose-dependently and time-dependently. In our experiments, we confirmed many dead cells, and we also confirmed that the cell death was apoptosis based on the detection of morphological nuclear change with separate globular structures and the activation of caspase-3. The induction of apoptosis by bisphosphonates was confirmed not only in the myeloma cell line already reported (HS-Sultan), but also in all the cell lines used in our current experiment, such as the lymphoblastic leukemia B cell line (CCRF-SB), the acute promyelocytic leukemia cell line (HL-60), the chronic myeloid leukemia cell lines (K562), the lymphoblastic leukemia $\mathrm{T}$ cell line (Jurkat), the acute lymphoblastic leukemia T cell line (MOLT-4) and the histiocytic lymphoma cell line (U937). YM175 showed a mild inhibitory effect on Jurkat and MOLT-4, whereas YM529 was confirmed to have a stronger apoptosis-inducing effect on these cell lines as compared with YM175. That is, YM529 was confirmed to inhibit cell proliferation at a lower concentration than YM175, which has a relatively more potent antitumor effect than existing bisphosphonates. The result is consistent with a report of Takahashi et al. ${ }^{19)}$ which described YM529 as one of the bisphosphonates with the most potent cytostatic effects on myeloma cells, and the same effect of the drug on hematopoietic tumor cells other than myeloma was observed. However, against CCRF-SB, both YM175 and YM529 showed only mild cytostatic effects, and the cytostatic effects of bisphosphonates may be mild on B cell line leukemia cells. In the present experiment, the reason for different efficacies with different cell types remains completely obscure, and further research on this topic is required in the future. The concentration of bisphosphonate YM529 that induces apoptosis in hematopoietic tumors in myeloma, breast cancer and the present experiment is clearly 10 times higher compared to the concentration that suppresses bone resorption of osteoclasts. However, since bisphosphonate accumulates in the bone, its concentration in the bone marrow is very high, suggesting that it may be very effective against bone marrow tumors, including bone metastatic tumors.

Based on the experimental results, YM529 was shown to induce apoptosis of hematopoietic tumor cells other than myeloma to a degree equivalent or superior to that in myeloma, and to induce apoptosis at a lower concentration as compared with YM175. Therefore, we conclude that further utilization of the drug can be expected in the future. 



HL-60
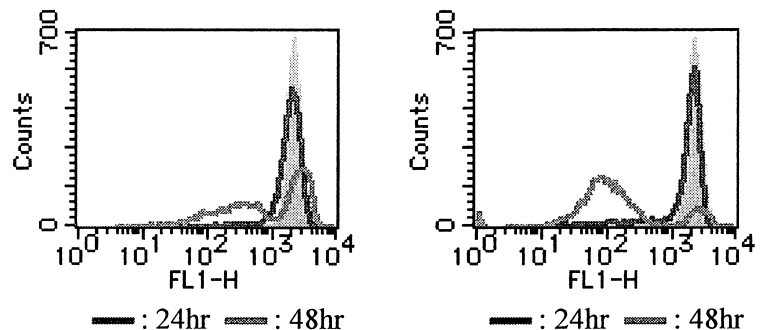

HS-Sultan
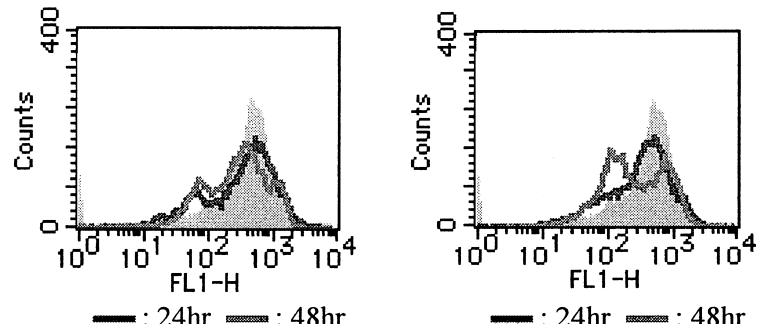

Jurkat
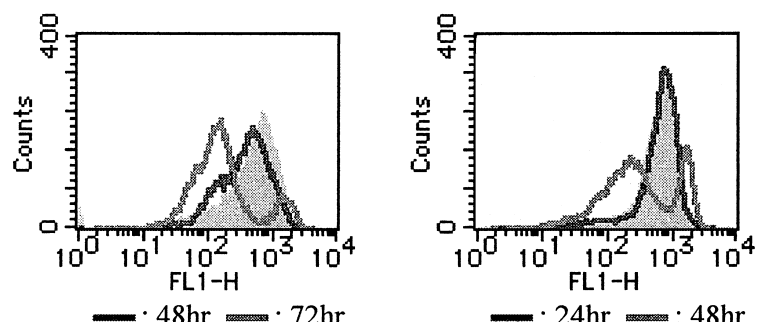

$: 24 \mathrm{hr}: 48 \mathrm{hr}$

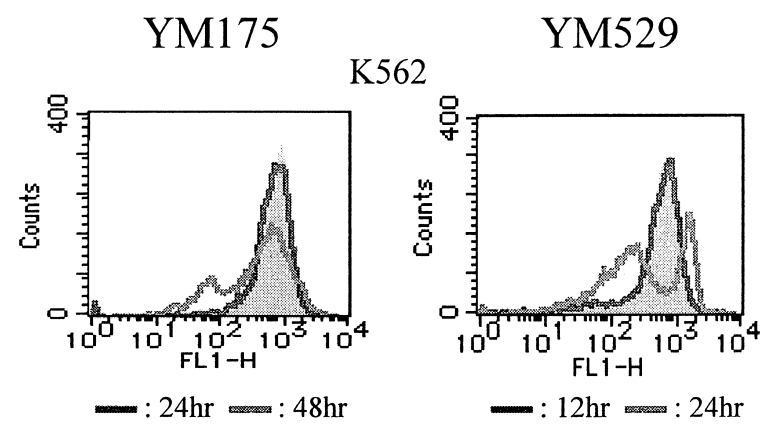

MOLT-4
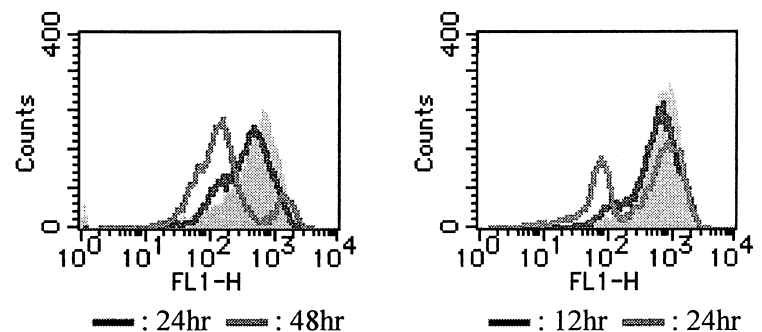

U937
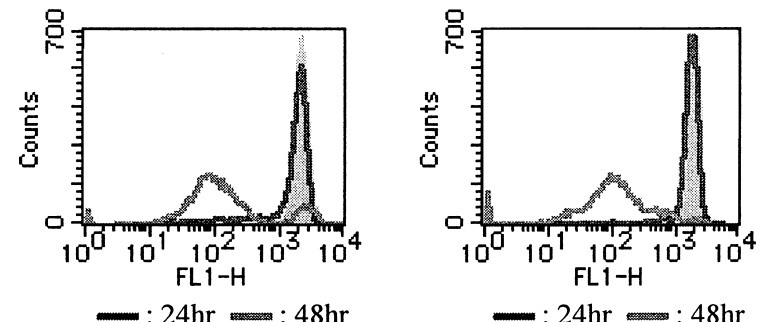

Fig. 4. Effects of YM529 and YM175 on the Mitochondrial Transmembrane Potential Mitochondrial transmembrane potential was decreased in cells treated with each of the drugs.

\section{REFERENCES}

1) Russell R. G. G., Rogers M. J., Bone, 25, 97-106 (1999).

2) Watts N. B., Harris S. T., Genant H. K., Wasnich R. D., Miller P. D., Jackson R. D., Licata A. A., Ross P., Woodson G. C., 3rd, Yanover M. J., N. Engl. J. Med., 323, 73-79 (1990).

3) Altman R. D., Johnston C. C., Khairi M. R. A., Wellman H., Serafini A. N., Sankey R. R., N. Engl. J. Med., 289, 1379-1384 (1973).

4) Hughes D. E., Wright K. R., Uy H. L., Sasaki A., Yoneda T., Roodman G. D., Mundy G. R., Boyce B. F., J. Bone Miner. Res., 10, 1478-1487 (1995).

5) Rodan G. A., Fleish H. A., J. Clin. Invest., 97, 2692-2696 (1996).

6) Rogers M. J., Chilton K. M., Coxon F. P., Lawry J., Smith M. O., Suri S., Russell R. G., J. Bone Miner. Res., 11, 1482-1491 (1996).

7) Boonekamp P. M., Lianne J. A., Wee-Pals V. D., Lennep M. M. L. V. W., Thesing C. W., Bijvoet O. L. M., Bone Miner. Res., 1, 27-39 (1986).

8) Huges D. E., MacDonald B. R., Russell R. G. G., Gowen M., J. Clin. Invest., 83, 1930-1935 (1989).

9) Nishikawa M., Akatsu T., Katayama Y., Yasutomo S., Kado S., Kugai N., Yamamoto M., Nagata N., Bone, 18, 9-14 (1996).

10) Fast D. K., Dowse R. F. C., Neuman W. F., Fleish H., Biochem. J., 172, 97-107 (1978)
11) Reitsma P. H., Teitelbaum S. L., Bijvoet O. L., Kahn A. J., J. Clin. Invest., 70, 927-933 (1982).

12) Yoneda T., Michigami T., Yi B., Williams P. J., Niewolna M., Hiraga T., Cancer, 88, 2979-2988 (2000).

13) Boissier S., Magnetto S., Frappart L., Cuzin B., Ebetino F. H., Delmas P. D., Clezardin P., Cancer Res., 57, 3890-3894 (1997).

14) Shipman C. M., Rogers M. J., Apperley J. F., Russell R. G., Croucher P. I., Br. J. Haematol., 98, 665-672 (1997).

15) Aparicio A., Gardner A., Tu Y., Savage A., Berenson J., Kichtenstein A., Leukemia, 12, 220-229 (1998).

16) Benford H. L., Frith J. C., Auriola S., Monkkonen J., Rogers M. J., Mol. Pharmcol., 55, 131-140 (1999).

17) Usui T., Kawakami R., Watanabe T., Higuchi S., J. Chromatogr, 652, 67-72 (1994).

18) Sasaki A., Kitamura K., Alcalde R. E., Tanaka T., Suzuki A., Etho Y., Matsumura T., Int. J. Cancer, 77, 279-285(1998).

19) Takahashi R., Shimazaki C., Inaba T., Okano A., Hatsuse M., Okamoto A., Hirai H., Ashihara E., Nakagawa M., Leukemia Res., 25, $77-83$ (2001).

20) Rogers M. J., Chilon K. M., Cixib F. P., Lawry J., Smith M. O., Suri S., Russell G. G., Bone Miner. Res., 11, 1482-1491 (1996).

21) Senaratne S. G., Pirianov G., Mansi J. L., Arnett T. R., Colston K. W., Br. J. Cancer, 82, 1459-1468 (2000). 